Jurnal Riset Manajemen Sains Indonesia (JRMSI) | Vol 12, No. 2, 2021 e-ISSN: 2301-8313 http://doi.org/10.21009/JRMSI

DOI: doi.org/10.21009/JRMSI.012.2.05

\title{
MENGUKUR KINERJA PENGEOLAAN DANA DESA BERBASIS KOMPETENSI MELALUI PARTISIPASI SEBAGAI VARIABEL MODERASI
}

\author{
Maya Yusnita \\ Fakultas Ekonomi Universitas Bangka Belitung \\ Email: mayayusnitaubb@gmail.com \\ Reko Dwi Salfutra \\ Fakultas Hukum Universitas Bangka Belitung \\ Email: dwisalfutra@gmail.com
}

\begin{abstract}
ABSTRAK
Tujuan penelitian ini adalah untuk mengetahui dan menganalisis kinerja pengelolaan dana desa berbasis kompetensi aparatur desa melalui partisipasi masyarakat sebagai variabel moderasi. Penelitian ini merupakan penelitian kombinasi dan bersifat eksplanatori (explanatory research) dengan pendekatan SEM Moderating menggunakan SmartPLS (Partial Least Square). Data penelitian adalah data primer yang diperoleh dari penyebaran kuesioner kepada 100 responden masyarakat Kecamatan Tempilang Kabupaten Bangka Barat. Hasil penelitian menunjukkan bahwa terdapat pengaruh positif variabel kompetensi aparatur desa dan partisipasi masyarkat terhadap kinerja pengelolaan dana desa. Variabel partisipasi masyarakat tidak memoderasi pengaruh kompetensi aparatur desa terhadap kinerja pengelolaan dana desa.
\end{abstract}

Kata Kunci: Kinerja, Kompetensi, Partisipasi 
Jurnal Riset Manajemen Sains Indonesia (JRMSI) | Vol 12, No. 2, 2021 e-ISSN: 2301-8313 http://doi.org/10.21009/JRMSI

\section{PENDAHULUAN}

Desentralisasi adalah penyerahan wewenang pemerintahan oleh pemerintah kepada daerah otonom untuk mengatur dan mengurus urusan pemerintahan dalam sistem Negara Kesatuan Republik Indonesia (Undang-Undang Nomor 32 Tahun 2004). Pada kerangka otonomi desa, segala bentuk urusan pemerintahan desa menjadi kewenangan desa, termasuk dalam hal pengelolaan keuangan desa (Prasetyo, 2014) dalam (Sari, 2017). Oleh karena itu, pemerintah mengeluarkan kebijakan yaitu pembentukan Alokasi Dana Desa (ADD) sebagai perwujudan dari desentralisasi keuangan menuju desa yang mandiri (Wida, 2017). Alokasi Dana Desa yang diterima pemerintah desa sebesar 30\% dipergunakan untuk biaya operasional penyelenggaraan pemerintahan desa, sedangkan sebesar $70 \%$ untuk pembangunan fisik dan pemberdayaan masyarakat desa (Saputra, 2016).

Kinerja pengelolaan keuangan desa akan menentukan tercapai atau tidaknya tujuan dana desa. Kinerja pengelolaan keuangan yang buruk yang ditandai dengan pencatatan dan pelaporan yang tidak konsisten dan sesuai standar dapat membuat proses evaluasi penggunaan dana menjadi suliit dilakukan. Lebih penting lagi adalah tingkat efisiensi dan efektivitas pengelolaan keuangan desa akan ditentukan oleh kemampuan para aparatur desa mengelola dana desa yang mereka miliki (Munti, 2017).

Menurut Amstrong (Moeheriono, 2012:6), kompetensi merupakan dimensi tindakan dari tugas, dimana tindakan tersebut dipakai oleh karyawan untuk menyelesaikan tugas pekerjaan mereka dengan memuaskan dan apa yang diberikan karyawan dalam bentuk yang berbedabeda dan tingkatan kinerjanya. Batasan ini secara implisit mengartikan bahwa ada hubungan antara kompetensi dengan kinerja pegawai (Makawi, 2015). Menurut Rudana (2005:6), kompetensi merujuk kepada pengetahuan (knowledge), keahlian (skills) dan kemampuan (abilities) yang dapat didemonstrasikan yang dilakukan dengan standar tertentu (Widyatama, 2017). Penelitian yang dilakukan oleh Yusuf Ardiansyah\&Lisa Harry Sulistiyowati (2018) menghasilkan bahwa terdapat pengaruh yang positif dan signifikan variabel kompetensi terhadap kinerja pegawai. Penelitian oleh Arif Widyatama, Lola Novita\&Diarespati (2017) menemukan bahwa kompetensi aparatur tidak berpengaruh signifikan terhadap akuntabilitas dalam pengelolaan Alokasi Dana Desa (ADD).

Intihanah dan Nur Afifa (2016) menghasilkan temuan bahwa partisipasi anggaran berpengaruh signifikan terhadap kinerja pemerintah. Apollo M. Nakwe, Holta Trandafili \& Joel Hughey (2013) dalam penelitiannya mengenai hubungan antara partisipasi masyarakat dan 
Jurnal Riset Manajemen Sains Indonesia (JRMSI) | Vol 12, No. 2, 2021 e-ISSN: 2301-8313 http://doi.org/10.21009/JRMSI

outcome dari 92 program pemberdayaan masyarakat, menghasilkan bahwa keduanya memiliki hubungan yang kuat dalam keberhasilan program tersebut.

\section{TELAAH PUSTAKA}

\section{Kompetensi}

Menurut Dunnetts dalam anonim, skill adalah kapasitas yang dibutuhkan untuk melaksanakan suatu rangkaian tugas yang berkembang dari hasil pelatihan dan pengalaman. Menurut Blanchard \& Thacker (2004) dalam anonim, skill seseorang tercermin dari seberapa baik seseorang dalam melaksanakan suatu kegiatan yang spesifik seperti mengoperasikan suatu peralatan, berkomunikasi efektif, atau mengimplementasikan suatu strategi bisnis (Hariyani, 2016).

\section{Kinerja}

Pengukuran kinerja diterapkan sebagai upaya untuk menjawab tuntutan publik atas kinerja organisasi publik yang meliputi produktivitas, keterbukaan dan akuntabilitas. Permintaan ini seiring dengan kecen-derungan yang berkembang di Negara maju yang menyatakan bahwa pengukuran kinerja adalah mekanisme untuk mewujudkan akuntabilitas (Pollitt, 2011:81-87, Epstein, 1988:129, Ghobadian \& Asworth, 1994:35-51, Kaplan dan Norton, 1996:21, de Lancer Julnes, 2008:65-78, Halachmi, 2002:370-374, Poister, 2003:325355, Van Dooren et al, 2010: 116-128).

\section{Partisipasi Masyarakat}

Partisipasi masyarakat dalam penganggaran harus dilakukan pada setiap tahapan dalam siklus anggaran mulai dari tahap persiapan anggaran (preparation), ratifikasi (approval/ratification), implementasi (implementation), dan pelaporan dan evaluasi (reporting and evaluation) (Mardiasmo, 2009: 70) dalam (Nuru, 2013).

Suatu program kegiatan akan berjalan lancar dan mencapai tujuan apabila masyarakat yang ikut berpartisipasi aktif dan memberikan persepsi dan partisipasi yang positif. Pidarta (dalam Mubyarto, 1984), partisipasi adalah pelibatan seseorang atau beberapa orang dalam suatu kegiatan. Keterlibatan dapat berupa keterlibatan mental dan emosi serta fisik dalam menggunakan semua kemampuan yang dimilikinya (berinisiatif) dalam kegiatan yang dilaksanakan (Isti, 2017).

Samuel (1999) mengatakan kurangnya partisipasi masyarakat selama ini disebabkan oleh rendahnya tingkat kesadaran masyarakat yang berkaitan dengan informasi, teknologi dan keterampilan. Harun (1995) juga menyatakan bahwa partisipasi masyarakat dipengaruhi oleh 
Jurnal Riset Manajemen Sains Indonesia (JRMSI) | Vol 12, No. 2, 2021 e-ISSN: 2301-8313 http://doi.org/10.21009/JRMSI

(1) faktor pendidikan, (2) tingkat pengetahuan, (3) tingkat kesadaran masyarakat terhadap lingkungannya, (4) pengembangan organisasi social di masyarakat (Budiman, 2013).

\section{HASIL DAN PEMBAHASAN}

\section{Gambaran Umum Objek Penelitian}

Objek dalam penelitian ini adalah masyarakat pada Kecamatan Tempilang Kabupaten Bangka Barat yang terdiri dari 4 (empat) desa yaitu Desa Buyan Kelumbi, Desa Penyampak, Desa Sangku, dan Desa Simpang Yul.

\section{Hasil Deskriptif Karakteristik Responden}

Tabel 1. Karakteristik Responden berdasarkan Usia

\begin{tabular}{cccc}
\hline No & Umur (Tahun) & Jumlah (Orang) & Persentase (\%) \\
\hline 1 & $<20$ & 3 & 3,0 \\
2 & $21-25$ & 26 & 26,0 \\
3 & $26-30$ & 17 & 17,0 \\
4 & $>30$ & 54 & 54,0 \\
& Total & $\mathbf{1 0 0}$ & $\mathbf{1 0 0}$ \\
\hline \multicolumn{2}{l}{ Sumber: Data Primer (2020) }
\end{tabular}

Berdasarkan Tabel 1 diatas, dapat disimpulkan bahwa responden didominasi usia lebih dari 30 tahun dengan persentase sebesar 54\%.

\begin{tabular}{cccc}
\multicolumn{4}{c}{ Tabel 2. Karakteristik Responden berdasarkan Jenis Kelamin } \\
\hline No & Jenis Kelamin & Jumlah (Orang) & Persentase (\%) \\
\hline 1 & Perempuan & 53 & 47,0 \\
2 & Laki-Laki & 47 & 53,0 \\
& Total & $\mathbf{1 0 0}$ & $\mathbf{1 0 0}$ \\
\hline
\end{tabular}

Sumber: Data Primer (2020)

Berdasarkan Tabel 2 diatas, dapat disimpulkan bahwa responden didominasi oleh jenis kelamin perempuan dengan persentase sebesar $53 \%$.

\begin{tabular}{cccc}
\multicolumn{4}{c}{ Tabel 3. Karakteristik Responden berdasarkan Pendidikan Terakhir } \\
\hline No & Pendidikan Terakhir & Jumlah (Orang) & Persentase (\%) \\
\hline 1 & SMA/Sederajat & 33 & 33,0 \\
2 & D3 & 1 & 1,0 \\
3 & S1 & 13 & 13,0 \\
4 & Lainnya & 52 & 53,0 \\
& Total & $\mathbf{1 0 0}$ & $\mathbf{1 0 0}$
\end{tabular}

Sumber: Data Primer (2020)

Berdasarkan Tabel 3 diatas, dapat disimpulkan bahwa karakteristik responden berdasarkan pendidikan terakhir didominasi oleh kategori lainnya sebesar 53\%. Kategori lainnya yaitu masyarakat dengan pendidikan terakhir Sekolah Dasar (SD) dan tidak sekolah. 
Jurnal Riset Manajemen Sains Indonesia (JRMSI) | Vol 12, No. 2, 2021 e-ISSN: 2301-8313 http://doi.org/10.21009/JRMSI

\section{Hasil Analisis Data}

\section{Evaluasi Model Struktural (Inner Model)}

Evaluasi inner model dilakukan untuk memastikan model struktural yang dibangun akurat dan andal. Pengujian inner model dapat dilakukan dengan tiga cara, diantaranya :

\section{Coefficient of Determination ( $R^{2}$ Value)}

Klasifikasi nilai $R^{2}$ value yaitu 0.75 dikategorikan memiliki model yang kuat, 0.50 dikategorikan memiliki model moderate, dan 0.25 dikategorikan memiliki model yang lemah.

\section{Tabel 4. Nilai $\mathbf{R}^{2}$ Value}

\begin{tabular}{cccc}
\hline Variabel & $\mathbf{R}^{\mathbf{2}}$ Value & $\mathbf{R}^{\mathbf{2}}$ Adjusted & Keterangan \\
\hline Kinerja (Y) & 0.737 & 0.729 & Moderate \\
\hline Sumber: Data Primer Diolah, 2020 & &
\end{tabular}

Tabel 4 diatas menunjukkan bahwa nilai R-square untuk variabel kompetensi aparatur desa dan partisipasi masyarakat terhadap variabel endogen kinerja pengelolaan dana desa yaitu sebesar 0,729 atau sebesar 72,90\%. Kondisi ini menunjukkan bahwa masih terdapat $37,10 \%$ dipengaruhi oleh faktor dan variabel lain yang tidak dijelaskan dalam penelitian ini.

\section{Effect Size $\left(f^{2}\right)$}

Nilai effect size dikategorikan memiliki kontribusi besar, menengah, dan kecil apabila berturut-turut memiliki nilai $0.35,0.15$, dan 0.02 .

Tabel 5. Nilai $f^{2}$ Value

\begin{tabular}{lcc}
\hline \multicolumn{1}{c}{ Variabel Eksogen } & $\mathbf{f}^{2}$ Value & Keterangan \\
\hline Kompetensi $(\mathrm{X})$ & 0.662 & Besar \\
Partisipasi $(\mathrm{Z})$ & 0.479 & Besar \\
\hline
\end{tabular}

Sumber: Data Primer Diolah, 2020

Berdasarkan Tabel 5 diketahui bahwa kontribusi variabel eksogen kompetensi aparatur desa terhadap variabel endogen kinerja pengelolaan dana desa masuk dalam kategori besar yakni senilai 0.662. Kontribusi variabel eksogen partisipasi masyarakat terhadap variabel endogen kinerja pengelolaan dana desa masuk dalam kategori besar yakni senilai 0.479.

\section{Predictive Relevance $\left(Q^{2}\right.$ Value $)$}

Predictive relevance merupakan uji yang dilakukan untuk mengukur seberapa baik nilai observasi dihasilkan oleh model. Apabila nilai $Q^{2}$ value $>0$, maka model memenuhi kriteria predictive relevance dan demikian sebaliknya. 
Tabel 6. Nilai $Q^{2}$ Value

\begin{tabular}{lccc}
\hline \multicolumn{1}{c}{ Variabel } & SSO & SSE & $\mathbf{Q}^{\mathbf{2}}$ (=1-SSE/SSO) \\
\hline Kompetensi (X) & 700.000 & 283.887 & 0.594 \\
Partisipasi (Z) & 700.000 & 325.968 & 0.534 \\
Kinerja (Y) & 1100.000 & 447.021 & 0.594 \\
\hline
\end{tabular}

Sumber: Data Primer Diolah, 2020

Berdasarkan Tabel 6 diketahui bahwa nilai $Q^{2}$ value masing-masing variabel laten adalah lebih besar dari 0 (nol), sehingga dapat dijelaskan bahwa model dalam penelitian ini memenuhi kriteria predictive relevance. Hal ini mengindikasikan bahwa data siap untuk dilanjutkan ke tahap pengujian inner model selanjutnya yaitu pengujian hipotesis.

\section{Pengujian Hipotesis}

Berdasarkan kriteria nilai t-value untuk uji hipotesis 2 arah (two tailed) dengan alpha 5\% adalah 1.96, maka uji hipotesis sebagai berikut:

Tabel 7. Nilai Path Coefficient Analisis Bootstrapping

\begin{tabular}{rcccccc}
\hline Uraian & Korelasi & Original Sample & $\mathbf{t}_{\text {statistik }}$ & $\mathbf{t}_{\text {value }}$ & Pvalue & Keputusan \\
\hline Hipotesis 1 & $\mathrm{X}>\mathrm{Y}$ & 0.512 & 5.883 & 1.96 & 0.000 & Diterima \\
Hipotesis 2 & $\mathrm{Z}>\mathrm{Y}$ & 0.436 & 4.826 & 1.96 & 0.000 & Diterima \\
Hipotesis 3 & $\mathrm{X}^{*} \mathrm{Z}>\mathrm{Y}$ & -0.054 & 0.964 & 1.96 & 0.335 & Tidak \\
\end{tabular}

Sumber: Data Primer Diolah, 2020

\section{Uji Efek Moderasi}

Evaluasi model uji efek moderasi dilakukan dengan melihat $R$-square dengan effect size 0,02; 0,15; dan 0,35. Menunjukkan bahwa model lemah, moderate dan kuat. Jika effect size yang dihasilkan nilainya lemah maka tidak akan berpengaruh terhadap efek moderasi.

Tabel 8. Total Effect Analisis Bootstrappin

\begin{tabular}{ccccc}
\hline Korelasi & $\begin{array}{c}\text { Original } \\
\text { Sample }\end{array}$ & $\mathbf{t}_{\text {statistik }}$ & $\mathbf{t}_{\text {value }}$ & Pvalue \\
\hline $\mathrm{X}>\mathrm{Y}$ & 0.512 & 5.865 & 1.96 & 0.000 \\
$\mathrm{Z}>\mathrm{Y}$ & 0.436 & 4.957 & 1.96 & 0.000 \\
$\mathrm{X} * \mathrm{Z}>\mathrm{Y}$ & -0.054 & 0.950 & 1.96 & 0.342 \\
\hline
\end{tabular}

Sumber: Data Primer Diolah, 2020

Berdasarkan Tabel 8 dapat diketahui bahwa variabel kompetensi aparatur desa (X) memiliki interaksi dengan variabel kinerja pengelolaan dana desa (Y) karena memiliki nilai tstatistik sebesar $5.865>1.96$ dan $p$-value sebesar $0.000<0.05$. Variabel partisipasi masyarakat (Z) memiliki interaksi dengan variabel Y karena memiliki nilai t-statistik sebesar 4.957>1.96 dan $p$-value sebesar $0.000<0.05$. 
Jurnal Riset Manajemen Sains Indonesia (JRMSI) | Vol 12, No. 2, 2021 e-ISSN: 2301-8313 http://doi.org/10.21009/JRMSI

Pada Tabel 8 juga dapat dilihat bahwa interaksi variabel kompetensi aparatur desa (X) dengan variabel kinerja pengelolaan dana desa (Y) yang dimoderasi oleh partisipasi masyarakat (Z) memiliki nilai t-statistik sebesar $0.950<1.96$ dan $p$-value sebesar $0.342>0.05$. Nilai tstatistik kompetensi aparatur desa (X) terhadap kinerja pengelolaan dana desa (Y) lebih kecil dibandingkan dengan nilai t-statistik kompetensi aparatur desa (X) terhadap kinerja pengelolaan dana desa (Y) tanpa variabel partisipasi masyarakat (Z) sebagai variabel moderasi yaitu t-statistik sebesar 5.865>1.96. Hal ini berarti variabel partisipasi masyarakat (Z) tidak memoderasi pengaruh kompetensi aparatur desa $(\mathrm{X})$ terhadap kinerja pengelolaan dana desa (Y).

\section{KESIMPULAN DAN SARAN}

Berdasarkan hasil penelitian dapat disimpulkan bahwa terdapat pengaruh yang positif variabel kompetensi aparatur desa dan partisipasi masyarkat terhadap kinerja pengelolaan dana desa. Variabel partisipasi masyarakat tidak memoderasi pengaruh kompetensi aparatur desa terhadap kinerja pengelolaan dana desa. Saran yang dapat diberikan yaitu Pemerintah Kabupaten Bangka Barat diharapkan dapat meningkatkan kompetensi aparatur desa khususnya di Kecamatan Tempilang agar dapat meningkatkan keahlian teknis aparatur dalam bekerja, seperti pelatihan kearsipan data, pelatihan pembuatan laporan keuangan dan pelatihan computer. Selain itu, diharapkan dapat memberikan penghargaan (reward) agar dapat meningkatkan motivasi dan partisipasi masyarakat dalam mendukung setiap program desa. Pemerintah desa di Kecamatan Tempilang diharapkan senantiasa mengutamakan prinsip kejujuran dan keterbukaan informasi dalam bekerja dengan mengoptimalkan website desa.

\section{UCAPAN TERIMA KASIH}

Penelitian ini didukung dan didanai sepenuhnya oleh Universitas Bangka Belitung (UBB) melalui Lembaga Penelitian dan Pengabdian kepada Masyarakat (LPPM) dalam skema Penelitian Dosen Tingkat Universitas (PDTU) Tahun Anggaran 2020 dengan Nomor Kontrak Penelitian: 193.D/UN50.11/PP/2020. Oleh karena itu, penulis mengucapkan terima kasih dan penghargaan setingginya kepada Universitas Bangka Belitung. 
Jurnal Riset Manajemen Sains Indonesia (JRMSI) | Vol 12, No. 2, 2021 e-ISSN: 2301-8313 http://doi.org/10.21009/JRMSI

\section{DAFTAR PUSTAKA}

Ardiansyah, Yusuf dan Lisa Harry Sulistiyowati. 2018. Pengaruh Kompetensi dan Kecerdasan Emosional terhadap Kinerja Pegawai. Jurnal Inspirasi Bisnis dan Manajemen, Vol. 2, (1), 2018, e-2579-9401, p-2579-9312.

Budiman, Ricky Arief dkk. 2013. Partisipasi dan Persepsi Masyarakat dalam Upaya Menjaga Mengelola Lingkungan Hidup dan Mempertahankan Predikat Kota Bersih. Jurnal Ilmu Lingkungan, ISSN: 1978-5283. 2013.

Ghozali, Imam. 2014. Structural Equation Modeling, Metode Alternatif dengan Partial Least Square (PLS). Badan Penerbit Universitas Diponegoro Semarang, ISBN: 979.704.300.2.

Hariyani, Diyah Santi dkk. 2016. Analisis Pengaruh Kompetensi Aparatur Pemerintahan Desa terhadap Penggunaan Teknologi Accounting Information System pada Desa-desa di Kabupaten Madiun. ASSETS: Jurnal Akuntansi dan Pendidikan, Volume 5 Nomor 2, Oktober 2016.

Intihanah dan Nur Afifa. 2016. Pengaruh Partisipasi Anggaran dan Good Governance terhadap Kinerja Pemerintah Daerah (Studi pada Dinas Kesehatan Kota Kendiri). Jurnal Akuntansi dan Keuangan Fakultas Ekonomi dan Bisnis, UHO.

Isti, Desti Nisa dkk. 2017. Persepsi dan Partisipasi Masyarakat terhadap Pemanfaatan Dana Desa untuk Pemberdayaan Masyarkat di Desa Kertajaya Kecamatan Padalarang Kabupaten Bangka Barat. Jurnal Pendidikan Luar Sekolah, Volume 1, Nomor 1, April 2017.

Kurniawan \& Irman Firmansyah. 2018. Problem and Solution of Village Accounting Implementation Using Analytic Network Process Approach. International Journal of Management and Applied Science, ISSN: 2394-792, Vol-4, Issue-5, May-2018.

Makawi, Umar, Normajatun\&Abdul Haliq. 2015. Analisis Pengaruh Kompetensi terhadap Kinerja Pegawai Dinas Perindustrian dan Perdagangan Kota Banjarmasin. Al-Ulum Ilmu Sosial dan Humaniora Volume 1 Nomor 1 Oktober 2015, ISSN: 2476-9576.

Munti, Finta\&Heru Fahlevi. 2017. Determinan Kinerja Pengelolaan Keuangan Desa: Studi pada Kecamatan Gandapura Kabupaten Bireuen Aceh. Jurnal Akuntansi dan Investasi, Vol. 18 No. 2, DOI: 10.18196/jai.180281.

Nakwe, Apollo, et al. 2013. Examining the Relationship between Community Participation and Program Oucomes in a Metaevaluation. Journal of Multidiciplinary Evaluation (JMDE), Vol. 9 Issue 20, 2013, ISSN 1556-8180. www.jmde.com.

Nuru, Ferdinant dkk. 2013. Pengaruh Pengetahuan Anggaran, Partisipasi Masyarakat dan Transparansi Kebijakan Publik terhadap Fungsi Dewan dalam Pengawasan Anggaran Pendapatan dan Belanja Daerah (APBD). Journal Accountability Vol. 2, No. 1, Juni 2013. 
Jurnal Riset Manajemen Sains Indonesia (JRMSI) | Vol 12, No. 2, 2021 e-ISSN: 2301-8313 http://doi.org/10.21009/JRMSI

Saputra, I Wayan. 2016. Efektivitas Pengelolaan Alokasi Dana Desa pada Desa Lembean Kecamatan Kintamani Kabupaten Bangli Tahun 2009-2014. Jurnal Jurusan Pendidikan Ekonomi (JJPE) Volume 6 Nomor 1 Tahun 2016.

Sari, Intan Mala\&M. Faisal Abdullah. 2017. Analisis Ekonomi Kebijakan Dana Desa terhadap Kemiskinan Desa di Kabupaten Tulungagung. Jurnal Ekonomi Pembangunan Vol. 15 No. 01, Juni 2017.

Sugiyono. 2016. Metode Penelitian Kombinasi (Mixed Methods). Bandung: CV Alfabeta.

Undang-Undang Nomor 32 Tahun 2004 tentang Pemerintahan Daerah.

Wida, Siti Ainul, Djoko Supatmoko, Taufik Kurrohman. 2017. Akuntabilitas Pengelolaan Alokasi Dana Desa (ADD) di Desa-desa Kecamatan Rogojampi Kabupaten Banyuwangi. E-Journal Ekonomi Bisnis dan Akuntansi, Volume IV (2): 148-152.

Widyatama, Arif, Lola Novita\&Diarespati. 2017. Pengaruh Kompetensi dan Sistem Pengendalian Internal terhadap Akuntabilitas Pemerintah Desa dalam Mengelola Alokasi Dana Desa (ADD). Berkala Akuntansi dan Keuangan Indonesia (BAKI), Vol. 2, No. 2, 2017. 